\title{
THE CAPABILITIES OF UNMANNED AERIAL VEHICLE FOR SLOPE CLASSIFICATION
}

\author{
N. M. Mokhtar, N. Darwin, M. F. M. Ariff ${ }^{1}$, Z. Majid, K. M. Idris
}

Geospatial Imaging and Information Research Group, Faculty of Built Environment and Surveying, Universiti Teknologi Malaysia, 81310, Skudai, Johor, Malaysia- murfiqah.mokhtar@gmail.com, (norhadija2, mfaridma, zulkeplimajid, khairulnizami)@utm.my

KEY WORDS: UAV, Slope classification, Digital Elevation Model (DEM), Orthophoto, Slope map

\begin{abstract}
:
Slope classification mapping is an important component of land suitability analysis for preventing landslides. This study aim to investigate the capabilities and application of Unmanned Aerial Vehicle (UAV) platform for slope classification. The objectives of this study such as investigating the capabilities of UAV for slope classification, generating Digital Elevation Model (DEM) and orthophoto from the image acquired and assessing the accuracy of DEM and orthophoto produced for slope classification. In this study, the aerial image was acquired using UAV at $60 \mathrm{~m}$ and $40 \mathrm{~m}$ altitude will then generates the DEM and orthophoto used to produce the slope map and classify the slope. The UAV data was validated with the check points observed from ground survey using GPS to obtain the Root Mean Square Error (RMSE) values. The RMSE value for UAV derived DEM at $60 \mathrm{~m}$ altitude is $\pm 0.234 \mathrm{~m}$ and $\pm 0.604 \mathrm{~m}$ for $\mathrm{X}$ and $\mathrm{Y}$ respectively. The average RMSE is $\pm 0.279 \mathrm{~m}$. The average RMSE value obtained from LiDAR derived DEM in previous research is $\pm 0.616 \mathrm{~m}$. The RMSE value for UAV derived DEM at $40 \mathrm{~m}$ altitude is $\pm 0.596 \mathrm{~m}$ and \pm 0.405 for $\mathrm{X}$ and $\mathrm{Y}$ respectively. The average RMSE is $\pm 0.334 \mathrm{~m}$. The average RMSE value obtained from LiDAR derived DEM in previous research is $\pm 0.450 \mathrm{~m}$. In conclusion, it shows that the RMSE value obtained from UAV derived DEM is smaller than the RMSE value obtained from LiDAR derived DEM. Hence, UAV is capable for the generation of slope map and slope classification.
\end{abstract}

\section{INTRODUCTION}

\subsection{Unmanned Aerial Vehicle for Slope Study}

Slope can be defined as the angle, inclination, steepness, or gradient of a straight line where it describes the steepness of the ground's surface. It is important to be map and analyse through elevation data that can be used for slope monitoring purposes to prevent landslides. One of the aspect need to be analysed is slope categories or classification through the production of slope mapping.

According to Tahar, 2012, the aerial manned platform has become an issue where it involves huge cost and it is normally suitable for projects with large budget, therefore, not practical for small project with low budget. In order to solve this problem, a new method called low-cost UAV are used to go through the restriction. Recently, Unmanned Aerial Vehicle (UAV) is an aircraft without a pilot on board can be used for mapping purposes.

UAV has been developed and used for countless practical purposes, from civilian tasks into military missions. According to Remondino et al., the UAV images and photogrammetrically derived 3D data or orthophotos are generally employed including forestry and agriculture, archaeology and cultural heritage, environmental surveying, traffic monitoring and also 3D reconstruction. Moreover, Rau et al. 2011 stated that UAV have been used for many mission and applications for research and projects due to its high mobility and high image resolution compared to satellite and airborne imagery.

According to Chao et al. 2007 other than UAV high power density batteries, long range and low power micro radio devices, cheap airframes and powerful micro-processors and motors, UAV also is one of the platform to acquire data at the area of interest which are difficult to access and it is safer and more user-friendly than manned aerial vehicle. UAV is a capable equipment that can be used to capture the Earth surface images from different altitude (Tahar, 2015).

In this study, UAV Photogrammetric has been used in order to obtain an accurate result for slope classification to prevent landslide. According to Hertwitz et al. 2004, a multirotor UAV system has been chosen because it is easy to operate, low maintenance, high flexibility and stability. According to Rau, 2011, UAV system have flown autonomously using the Global Navigation Satellite System (GNSS) for many years.

Uysal et al. 2015 stated that the digital camera attached to the UAV for capturing aerial images to produce the orthophoto and Digital Elevation Model (DEM). DEM is an important topographic product and essential demand for many applications (Salleh et al. 2015). Therefore, this study analysed the slope map based on the DEM produced by using image processing to classify the slope area.

According to Tahar et al. 2015, there are many factors that can cause slope failure. One of the factors for slope failure is underground water that flows in the unstable ground. Many researches have been carried out to monitor this problem such as assessment of slope stability, mapping of slope risk area and in situ measurement of the prone area. Slope instability caused many losses and huge economics expenses especially in tropical countries. Hence, many techniques has been used to generate slope map at the risk area. Light detection and ranging (LiDAR), manned aerial photograph, terrestrial laser scanner (TLS), satellite imagery and field surveying are the techniques that has been used to acquire data for slope mapping generation.

However, those techniques that have been used for slope mapping are very expensive and need a professional surveyor to 
practice the survey work based on Tahar et al. 2012. Table 1 shows the slope classification according to Ministry of Water, Land and Natural Resources.

\begin{tabular}{|c|c|c|c|}
\hline Class 1 & Class 2 & Class 3 & Class 4 \\
\hline Terrain & Terrain & Terrain & Terrain \\
with slope & with slope & with slope & with slope \\
between $0^{\circ}$ to & between $10^{\circ}$ & between $20^{\circ}$ & more than \\
$10^{\circ}$ & to $20^{\circ}$ & to $30^{\circ}$ & $30^{\circ}$ \\
\hline
\end{tabular}

Table 1. Slope Classification

The accuracy obtained from UAV data will be carried out using the method of Root Mean Square Error (RMSE). The RMSE equation will be used to calculate the difference between the coordinate of Check Points (CPs) obtained from UAV, GPS and LiDAR. According to Uysal et al. 2015, the RMSE equation is known as a standard deviation method to obtain for the purpose of determining the UAV data accuracy.

\subsection{Current Technique in Slope Mapping Studies}

There were several techniques that have been used in mapping the slope classification and stability such as Inclinometer, Piezometer, Radar System and Remote Sensing and Geographical Information Systems (GIS).।

Piezometer is used to measure fine pore pressure for assessing the effectiveness of water production processes. The importance of pressure in fine pores especially absorption at the geological boundary is responsible for most slope instability. Water pressure data is necessary to maintain the stability of the slope as the water behind the rock slope reduces the holding force and can add force that moves over the unstable rock. Furthermore, vents should be thoroughly inspected to detect new zones of movement after heavy rain.

Synthetic Aperture Radar (SAR) technique was originally a surface mapping radar specially designed for both aircraft and satellite use. SAR was used to produce high quality DEMs and to identify disturbances that occur on the surface of the Earth. Interferometric Synthetic Aperture Radar (IFSAR) uses a variation of SAR images of various time to produce map of the changes and this technique successfully produces a map of land surface movement changes due to earthquake, volcanic activity and mining process. It can also be used to monitor the change of slope or landslide instability. The advantages of IFSAR is it can work in almost all weather conditions, capable of penetrating fog, mist, rain, clouds and can work in either day or night.

Inclinometer consist of a casing placed on the ground through a suspected area of movement. The ends of the casing are considered fixed so that the profile of the transitional profile can be calculated. The casing has a curved engraving on the edges that serves as the basis for the detector unit. The touch and rock movement around the casing will be measured by specifying the angle of detector unit at certain point along the assembly. The information taken from the inclinometer is very important as a slope instability research material for the purpose of to obtain the zone that is moved due to pressure, to determine the moved zone is flat or rotating and to measure movement along the movable zone and determine whether the movement is fixed, persistent or otherwise.

Remote sensing and Geographical Information Systems (GIS) technique is the most widely used for monitoring landslides because it does not just produce an image of the monitored area, but can also speed up the process of obtaining incident information. With the variation of remote sensing data scale, some map parameters can be produces, which emphasize the large scale mapping map. GIS provides excellent imaging services for monitoring purposes due to the ability to manipulate spatial data in large quantities and provide visual manipulation results. It is clear that the use of remote sensing and GIS is an excellent technique used to monitor landslides and slope.

Currently, UAV has become a new surveying technique that uses the concept of photogrammetry to obtain the aerial image. Nowadays, UAV can be useful for mapping and scientific research because UAV can reach the area that are not accessible other than being cheaper and less time consuming compared to ground survey technique. Slope can be observe using different technique such as Inclinometer, Piezometer, Radar System and Remote Sensing and Geographical Information Systems (GIS). This study was focused on how to classify slope by using UAV.

This study has been carried out by using UAV Photogrammetric method to determine the capabilities of UAV for slope classification and the accuracy for the DEM generated. Figure 1 shows the study area which was located at Faculty of Built Environment and Surveying.

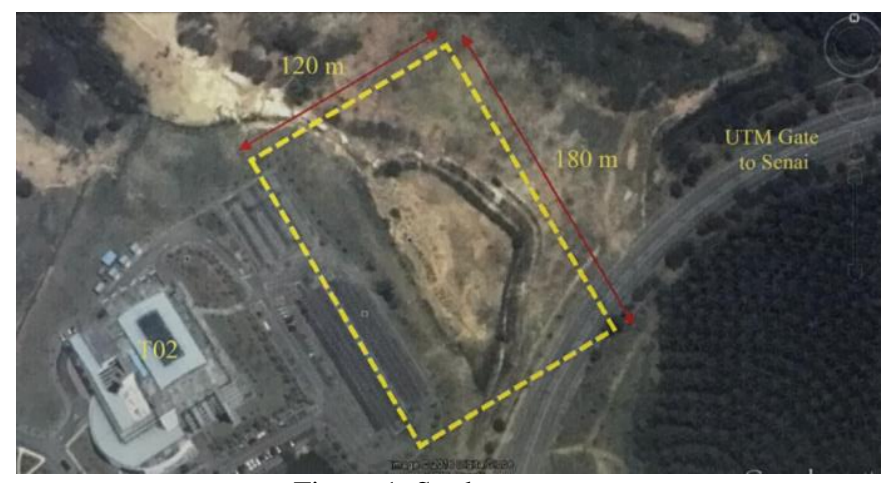

Figure 1. Study area

To find out the capabilities of the UAV for slope classification, the accuracy of the orthophoto and DEM need to be evaluated. The orthophoto and DEM will be generated from the aerial images acquired and the accuracy of orthophoto and DEM are assessed for slope classification.

\section{METHODOLOGY}

This study involves planning, observation and processing in order to achieve the aim of the study. The method and process of this study are as shown in Figure 2.

The survey was carried out throughout this phase after a few planning has been done. A proper flight planning has been done to ease the process of collecting data. The flight planning was planned using DJI Go Applications and the aerial image was collected using DJI Inspire 1 while the Ground Control Points (GCPs) and Check Points (CPs) was observed using GPS Topcon GR-5. Figure 3 shows the distribution of GCPs and CPs at the study area. 
The International Archives of the Photogrammetry, Remote Sensing and Spatial Information Sciences, Volume XLII-4/W16, 2019 6th International Conference on Geomatics and Geospatial Technology (GGT 2019), 1-3 October 2019, Kuala Lumpur, Malaysia

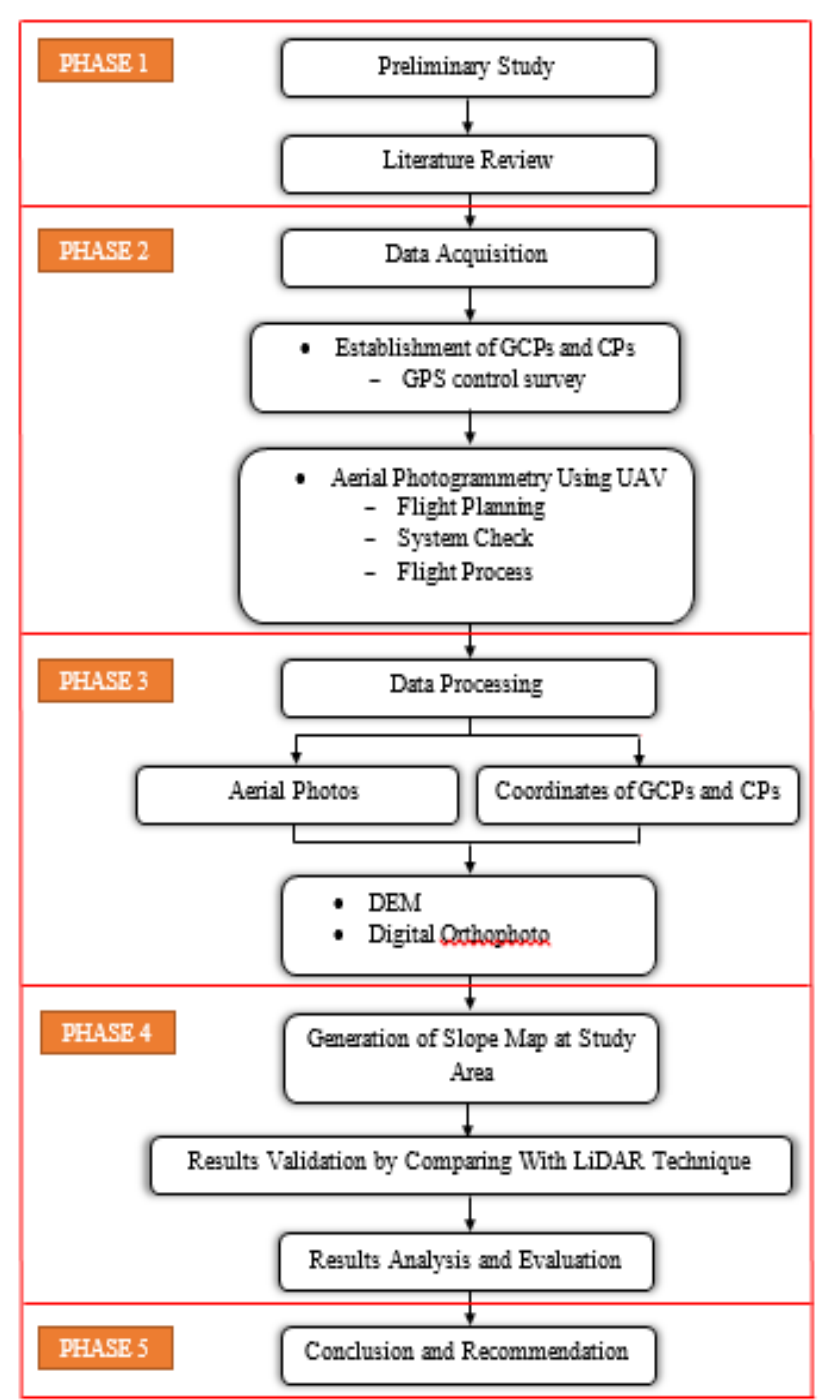

Figure 2. Flowchart of Research Methodology

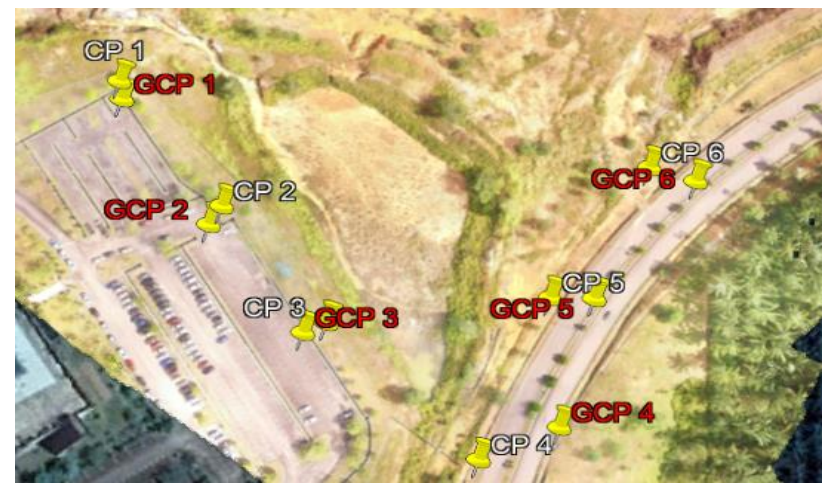

Figure 3. GCPs and CPs Distribution at study area

According to Agisoft Photoscan Professional manual, the minimum number of GCPs required for exterior orientation is 5 GCPs. In this study, 6 GCPs was established. GPS Rapid Static method was used to observe each GCPs and CPs for 15 minutes. According to Rusli, 2017, this method is suitable to establish control point at wide area with sub-meter accuracy. From this method, the coordinates of the GCPs and CPs was obtained after the processing of GPS data has been done.

The base station was set up at a reference mark near the study area. The GPS rover were then set up at other GCPs and CPs and the observation was carried out for 15 minutes each point. Figure 4 shows the GPS set up for observation. After done observing all points, the GPS data was downloaded and processed using Trimble Total Control (TTC) software. Figure 5 shows the TTC software during single baseline processing.

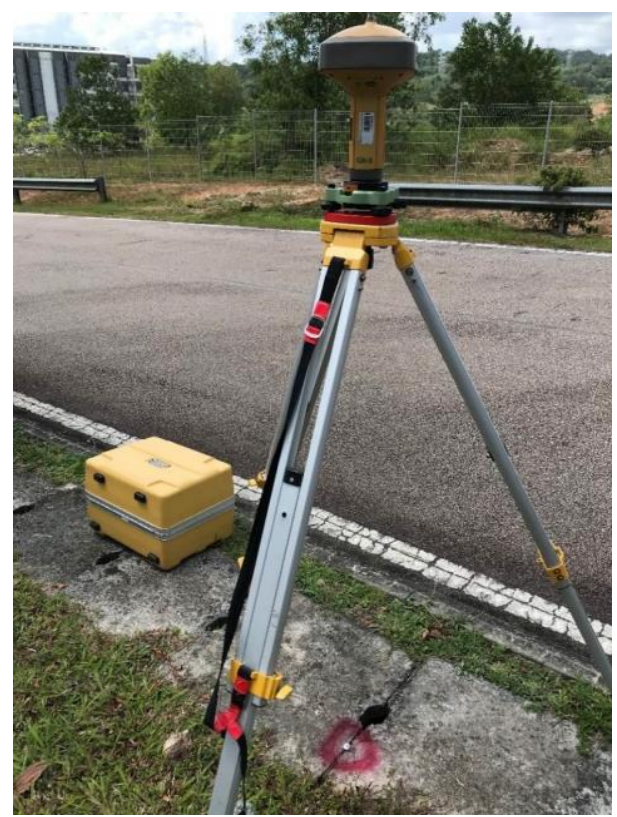

Figure 4. GPS Observation

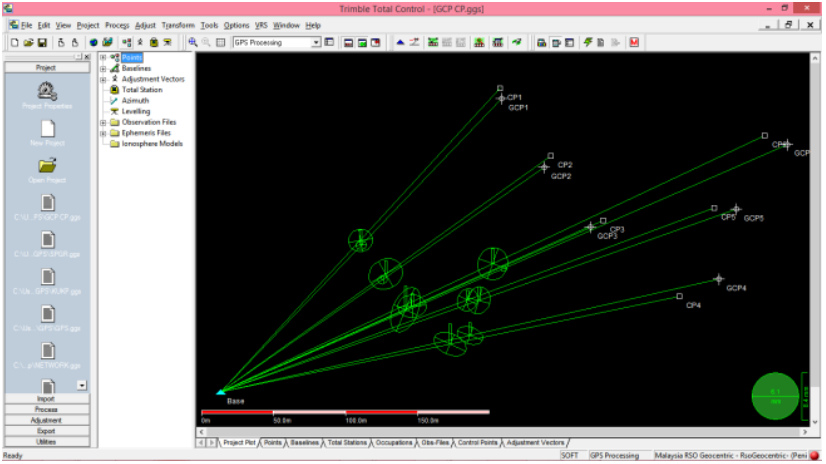

Figure 5. TTC Software during Single Baseline Processing

UAV flight planning can be carried out automatically using software and application that compliments the UAV. In this study, flight planning was done using DJI Go Application that can set automatically the specification such as flight lines, flying altitudes, side and end lap, tilt and crab tolerances.

This applications was programmed with algorithm to compute the specification for flight planning. User are required to insert the flying height, side and end lap, and other specification in the application. The flight map will be produced automatically as in Figure 6.

Figure 7 shows the step to obtain the aerial image. The aerial image data was collected using a digital camera, Xenmuse X3 that is placed on the DJI Inspire 1. Figure 8 and Figure 9 shows the camera placed on the UAV and the UAV used in this study respectively 
The International Archives of the Photogrammetry, Remote Sensing and Spatial Information Sciences, Volume XLII-4/W16, 2019 6th International Conference on Geomatics and Geospatial Technology (GGT 2019), 1-3 October 2019, Kuala Lumpur, Malaysia

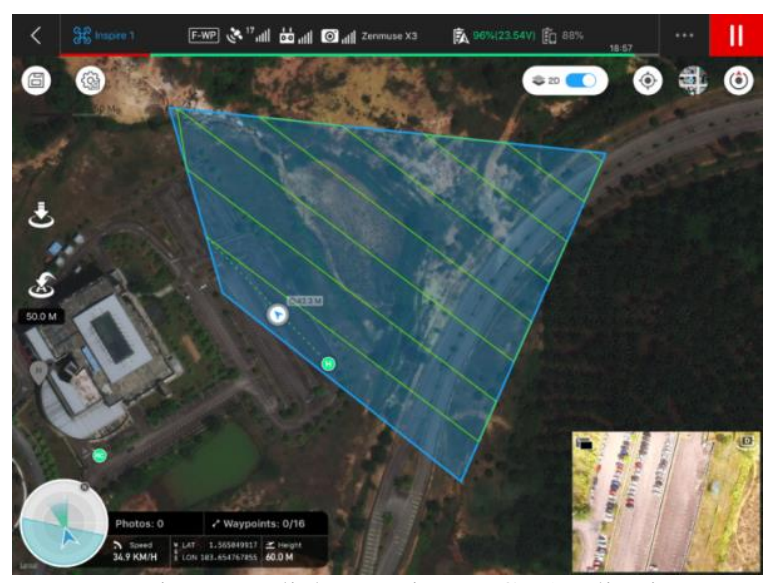

Figure 6. Flight Map in DJI Go Application

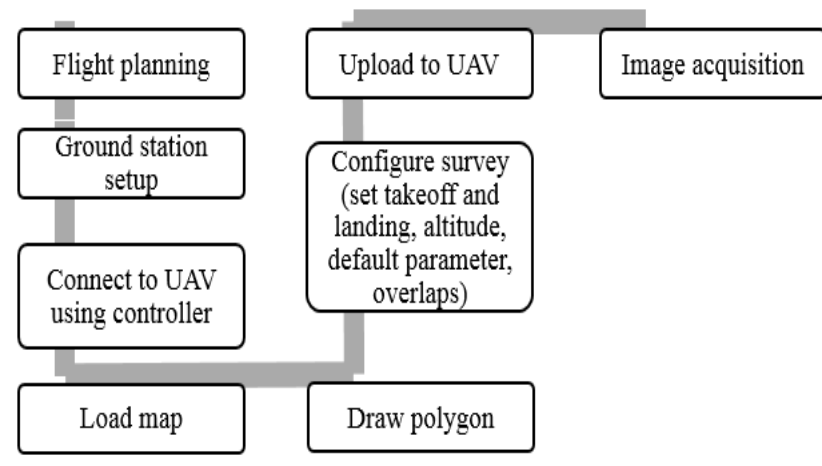

Figure 7. Flow of Aerial Image Acquisition

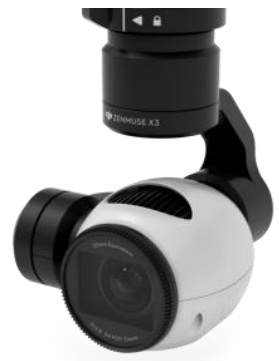

Figure 8. Xenmuse X3 Camera

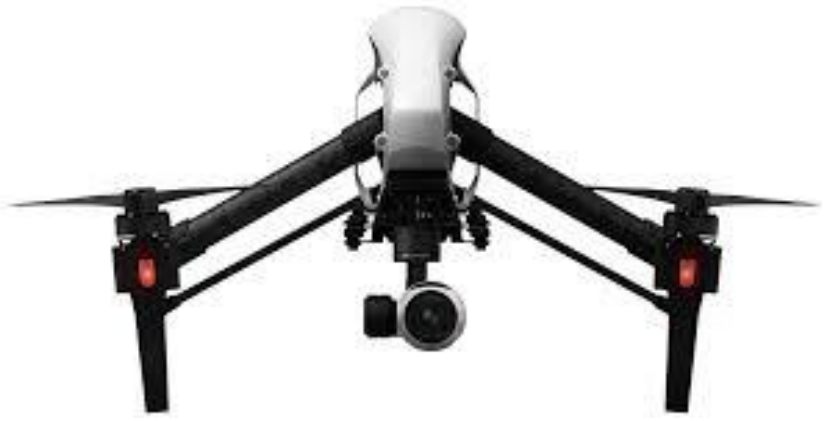

Figure 9. Multirotor UAV DJI Inspire 1

The flight line was designed before the flying phase to cover the whole study area by using DJI Go Application. The area of data acquisition was setup and the flight line was generated automatically using the application. Table 2 shows the flight planning information.

\begin{tabular}{|c|c|}
\hline INFORMATION & SPECIFICATION \\
\hline FLIGHT LINES & 7 \\
\hline GROUND RESOLUTION & $2.6 \mathrm{~cm} / \mathrm{px}$ \\
\hline IMAGE CAPTURED & 96 \\
\hline FLYING SPEED & $20.9 \mathrm{~km} / \mathrm{h}$ \\
\hline ALTITUDE & $60 \mathrm{~m}$ \\
\hline SIDE LAP & $75 \%$ \\
\hline END LAP & $75 \%$ \\
\hline
\end{tabular}

Table 2. Flight Planning Information

Subsequently, the flight was launched. The UAV has flown to the predefined flying altitude and the flight direction was following the setting done during flight planning. After the flying finished, the UAV will return to home point automatically. Hence, the aerial image acquisition phase was done.

Aerial images was processed using Agisoft Photoscan Professional software. Based on Rusli, 2017, Agisoft Photoscan Professional is a stand-alone software product that performs photogrammetric processing of digital images and generates 3D spatial data to be used in surveying works, GIS application, cultural heritage documentation and visual effects production as well as for indirect measurements of objects of various scales. According to Uysal et al. 2015, Agisoft Photoscan software is advanced in UAV applications and allows to generate DEM and Orthophoto in willed coordinate system.

Agisoft Photoscan Professional features photogrammetric triangulation that process various types of imagery including aerial and close-range. It also features dense point cloud editing and classification, generate and export orthomosaic and DEM other than measures distances, areas and volumes. In this study, the DEM must be filtered to get the best ground data before generating and classifying the slope. The DEM was filtered in Agisoft Photoscan Professional Software. Figure 10 shows the flow of image processing in Agisoft Photoscan Professional software.

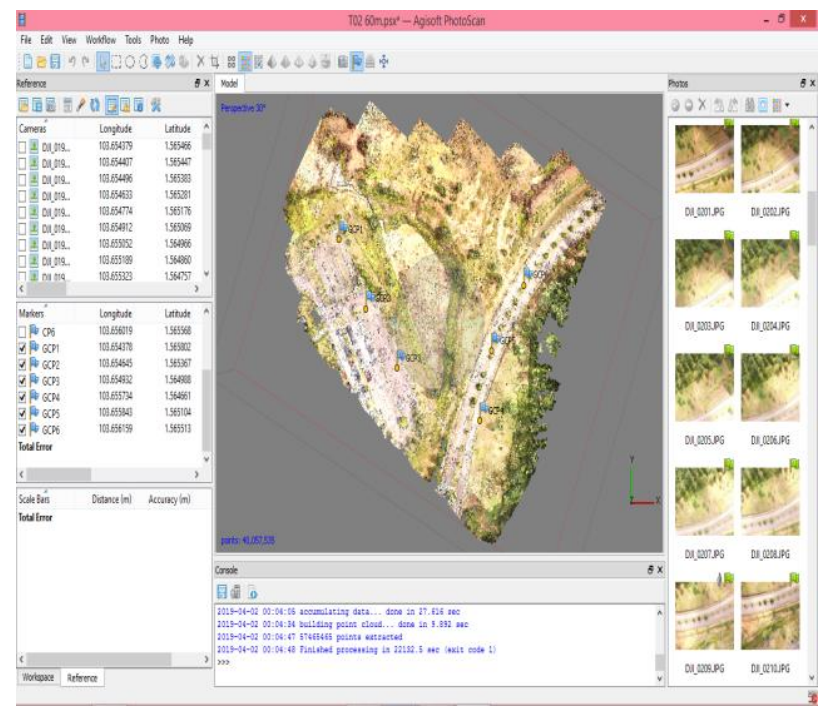

Figure 11. Agisoft Photoscan Professional Software during Image Processing Phase

All images captured was processed and 6 GCPs was registered during the exterior orientation as a full control and the accuracy was maintained by checking the processing RMSE value not exceeding $1.0 \mathrm{~m}$. 
The International Archives of the Photogrammetry, Remote Sensing and Spatial Information Sciences, Volume XLII-4/W16, 2019 6th International Conference on Geomatics and Geospatial Technology (GGT 2019), 1-3 October 2019, Kuala Lumpur, Malaysia

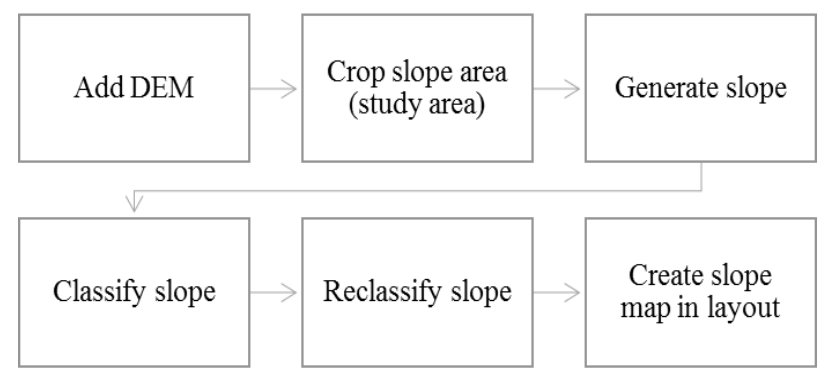

Figure 12. Flow of Slope Map Generation and Classification in ArcGIS Software

According to Salleh et al. 2015, the slope map is generated from the DEM of aerial image. Figure 12 shows the flow of slope map generation and classification. Slope tools in ArcGIS has been used to generate the slope at the study area. The slope are then classified using Analyst Tools in ArcGIS. The slope is classified into 4 classes according to The Ministry of Water, Land and Natural Resources which are as shown in Table 3.

\begin{tabular}{|c|c|}
\hline $\begin{array}{c}\text { SLOPE CLASS } \\
\text { (DEGREE) }\end{array}$ & $\begin{array}{c}\text { SLOPE RANGE } \\
\text { (DEGREE) }\end{array}$ \\
\hline $\mathbf{1}$ & $0^{\circ}-10^{\circ}$ \\
\hline $\mathbf{2}$ & $10^{\circ}-20^{\circ}$ \\
\hline $\mathbf{3}$ & $20^{\circ}-30^{\circ}$ \\
\hline $\mathbf{4}$ & $>30^{\circ}$ \\
\hline
\end{tabular}

Table 3. Slope Classification

\section{RESULTS AND ANALYSIS}

The generated orthophoto and DEM are the output of this study. Figure 13 and Figure 14 shows the orthophoto generated while the DEM generated are shown in Figure 15 and Figure 16 for $40 \mathrm{~m}$ and $60 \mathrm{~m}$ altitude respectively.

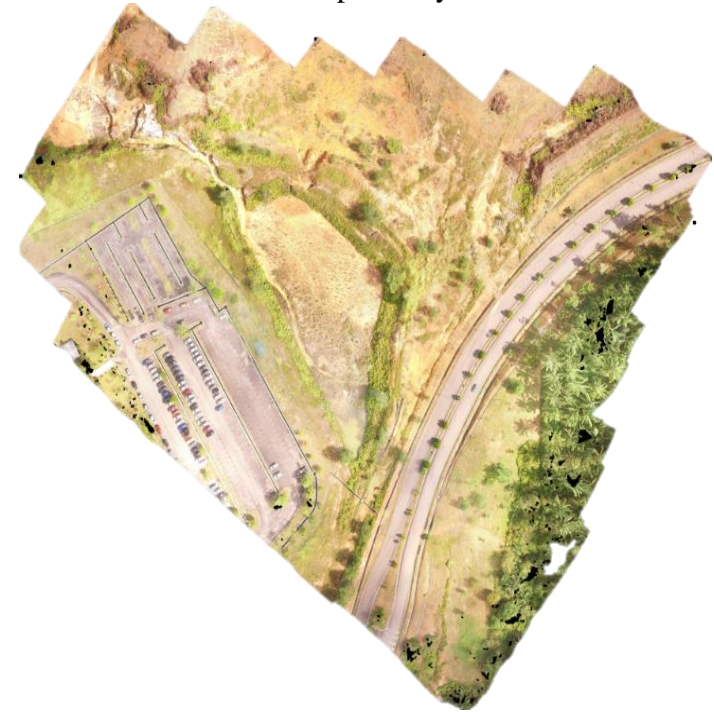

Figure 13. Orthophoto Generated at $60 \mathrm{~m}$ Altitude

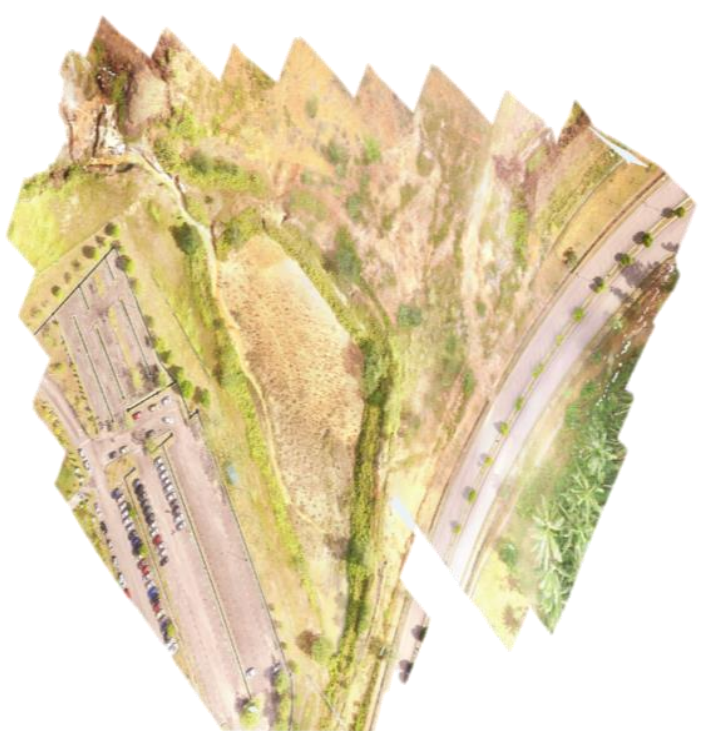

Figure 14. Orthophoto Generated at 40m Altitude

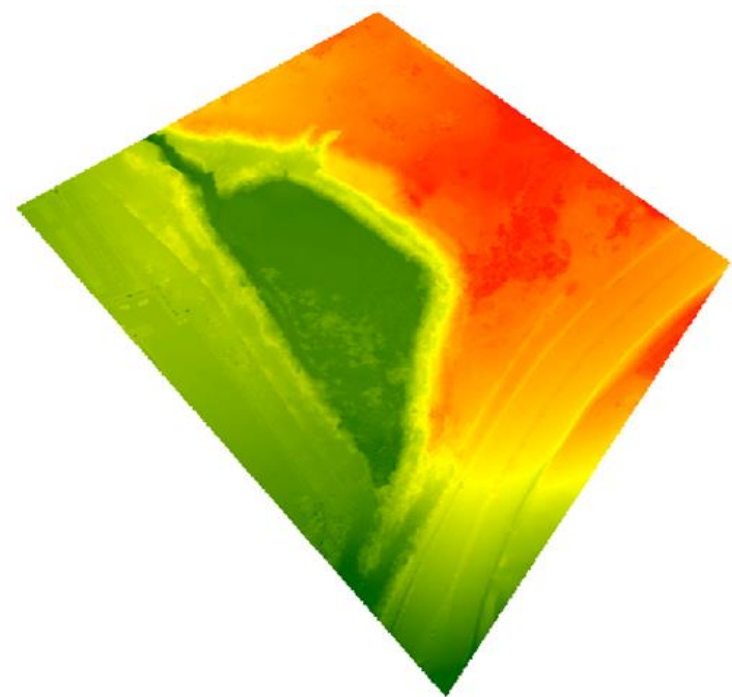

Figure 15. DEM Generated at 60m Altitude

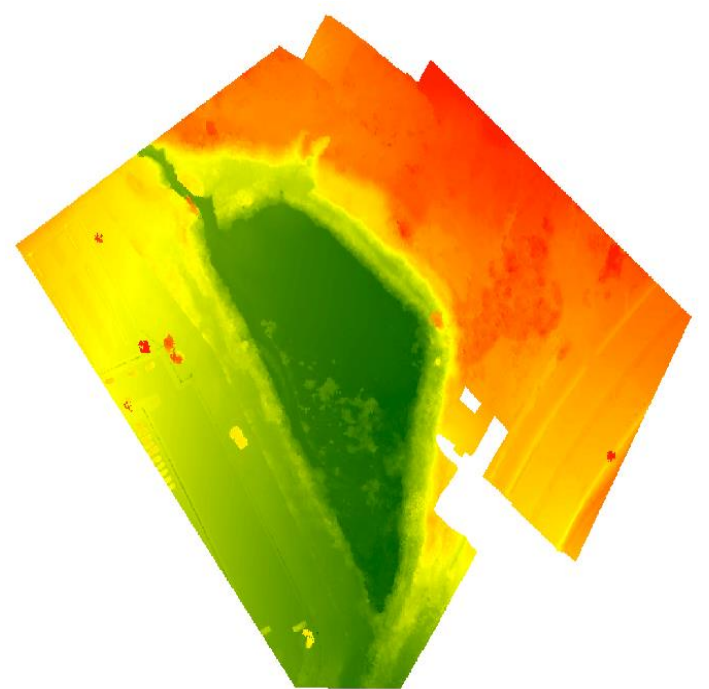

Figure 16. DEM Generated at 40m Altitude 
The data was analysed in order to investigate the capabilities of UAV for slope classification. The result was evaluated and analysed to assess the accuracy of DEM and orthophoto produced. The accuracy assessment for UAV data was carried out through the Root Mean Square Error (RMSE) method. The RMSE value indicates the accuracy of the DEM and orthophoto.
The RMSE equation was used to obtain the RMSE value of the CPs observed using GPS and the CPs from the UAV images at $60 \mathrm{~m}$ and $40 \mathrm{~m}$ altitude. The RMSE equation was also used to obtain the RMSE value of UAV derived DEM and LiDAR derived DEM at $60 \mathrm{~m}$ and $40 \mathrm{~m}$ altitude. Table 4 and Table 5 show the accuracy assessment for orthophoto and DEM at $60 \mathrm{~m}$ altitude and $40 \mathrm{~m}$ altitude respectively.

\begin{tabular}{|c|c|c|c|c|c|c|c|c|c|}
\hline \multirow{2}{*}{$\begin{array}{l}\text { Check } \\
\text { Point }\end{array}$} & \multicolumn{3}{|c|}{ TOPCON GR-5 (GPS) } & \multicolumn{3}{|c|}{ DJI INSPIRE 1 (UAV) } & \multicolumn{3}{|c|}{ DIFFERENCES } \\
\hline & $\mathrm{X}(\mathrm{m})$ & $\mathrm{Y}(\mathrm{m})$ & $\mathrm{H}(\mathrm{m})$ & $\mathrm{X}(\mathrm{m})$ & $\mathrm{Y}(\mathrm{m})$ & $\mathrm{H}(\mathrm{m})$ & $\mathrm{X}(\mathrm{m})$ & $\mathrm{Y}(\mathrm{m})$ & $\mathrm{H}(\mathrm{m})$ \\
\hline CP 1 & 628651.249 & 173165.980 & 22.907 & 628650.732 & 173165.838 & 22.896 & 0.517 & 0.142 & 0.011 \\
\hline CP 3 & 628722.679 & 173073.681 & 21.617 & 628722.698 & 173073.056 & 22.409 & -0.019 & 0.625 & -0.792 \\
\hline $\mathrm{CP} 4$ & 628775.503 & 173020.639 & 23.156 & 628774.904 & 173020.208 & 23.037 & 0.599 & 0.431 & 0.119 \\
\hline CP 5 & 628799.762 & 173082.495 & 26.795 & 628799.968 & 173082.232 & 27.668 & -0.206 & 0.263 & -0.873 \\
\hline \multirow[t]{3}{*}{$\mathrm{CP} 6$} & 628834.914 & 173132.997 & 29.760 & 628834.608 & 173132.581 & 30.358 & 0.306 & 0.416 & -0.598 \\
\hline & & & & & \multicolumn{2}{|c|}{ RMSE } & 0.391 & 0.409 & 0.593 \\
\hline & & & & & \multicolumn{2}{|c|}{ Average RMSE } & \multicolumn{3}{|c|}{0.464} \\
\hline
\end{tabular}

Table 4. Accuracy Assessment for Check Points at 60m Altitude

\begin{tabular}{|c|c|c|c|c|c|c|c|c|c|}
\hline \multirow{2}{*}{$\begin{array}{l}\text { Check } \\
\text { Point }\end{array}$} & \multicolumn{3}{|c|}{ TOPCON GR-5 (GPS) } & \multicolumn{3}{|c|}{ DJI INSPIRE 1 (UAV) } & \multicolumn{3}{|c|}{ DIFFERENCES } \\
\hline & $\mathrm{X}(\mathrm{m})$ & $\mathrm{Y}(\mathrm{m})$ & $\mathrm{H}(\mathrm{m})$ & $\mathrm{X}(\mathrm{m})$ & $\mathrm{Y}(\mathrm{m})$ & $\mathrm{H}(\mathrm{m})$ & $\mathrm{X}(\mathrm{m})$ & $\mathrm{Y}(\mathrm{m})$ & $\mathrm{H}(\mathrm{m})$ \\
\hline CP 1 & 628651.249 & 173165.980 & 22.907 & 628651.368 & 173165.222 & 22.475 & -0.119 & 0.758 & 0.432 \\
\hline $\mathrm{CP} 2$ & 628686.353 & 173118.712 & 22.006 & 628687.205 & 173118.831 & 22.974 & -0.852 & -0.119 & -0.968 \\
\hline CP 3 & 628722.679 & 173073.681 & 21.617 & 628722.953 & 173073.975 & 21.366 & -0.274 & -0.294 & 0.251 \\
\hline \multirow[t]{3}{*}{ CP 6} & 628834.914 & 173132.997 & 29.760 & 628834.880 & 173132.883 & 29.197 & -0.034 & 0.114 & 0.563 \\
\hline & & & & & \multicolumn{2}{|c|}{ RMSE } & 0.452 & 0.416 & 0.613 \\
\hline & & & & & \multicolumn{2}{|c|}{ Average RMSE } & \multicolumn{3}{|c|}{0.493} \\
\hline
\end{tabular}

Table 5. Accuracy Assessment for Check Points at 40m Altitude

As depicted in Table 4, the RMSE value for check points from $60 \mathrm{~m}$ altitude data is below than $1 \mathrm{~m}$. The RMSE value for coordinate $\mathrm{X}$ and $\mathrm{Y}$ is $\pm 0.391 \mathrm{~m}$ and $\pm 0.409 \mathrm{~m}$ respectively. Based on the previous research, the RMSE for $\mathrm{X}$ and $\mathrm{Y}$ is $\pm 0.415 \mathrm{~m}$ and $\pm 0.159 \mathrm{~m}$ (Udin et al., 2012). The RMSE value for coordinate $H$ is $\pm 0.593 \mathrm{~m}$. The average RMSE is $\pm 0.464 \mathrm{~m}$. This average RMSE value is acceptable compared to the average RMSE value in the previous research done which is $\pm 0.460 \mathrm{~m}$ [1].

As shown in Table 5, the RMSE value for check points from $40 \mathrm{~m}$ altitude data is lower than $1 \mathrm{~m}$. The RMSE value for coordinate $\mathrm{X}$ and $\mathrm{Y}$ is $\pm 0.452 \mathrm{~m}$ and $\pm 0.416 \mathrm{~m}$ respectively. From the previous research, the RMSE for $X$ and $Y$ is $\pm 0.411 \mathrm{~m}$ and $\pm 0.156 \mathrm{~m}$ (Udin et al. 2012). The RMSE value for coordinate $\mathrm{H}$ is \pm 0.613 . The average RMSE is \pm 0.493 . From this comparison, it shows that $60 \mathrm{~m}$ altitude data have smaller RMSE value than $40 \mathrm{~m}$ altitude data. The smaller RMSE value indicates higher accuracy (Azmi et al. 2014).

Table 6 depicts the RMSE value for UAV derived DEM at $60 \mathrm{~m}$ altitude is $\pm 0.234 \mathrm{~m}$ and $\pm 0.604 \mathrm{~m}$ for $\mathrm{X}$ and $\mathrm{Y}$ respectively. The average RMSE is $\pm 0.279 \mathrm{~m}$. The average RMSE value obtained from LiDAR derived DEM in previous research is $\pm 0.616 \mathrm{~m} \mathrm{[3]}$. As shown in Table 7, the RMSE value for UAV derived DEM is $\pm 0.596 \mathrm{~m}$ and \pm 0.405 for $\mathrm{X}$ and $\mathrm{Y}$ respectively. The average RMSE is $\pm 0.334 \mathrm{~m}$. The average RMSE value obtained from LiDAR derived DEM in previous research is $\pm 0.450 \mathrm{~m}$ [3].
From this result, it shows that the RMSE value obtained from UAV derived DEM is smaller than the RMSE value obtained from LiDAR derived DEM. Hence, UAV is capable for slope map generation and classification of slope. Figure 17 shows the comparison of RMSE value between UAV and LiDAR derived DEM.

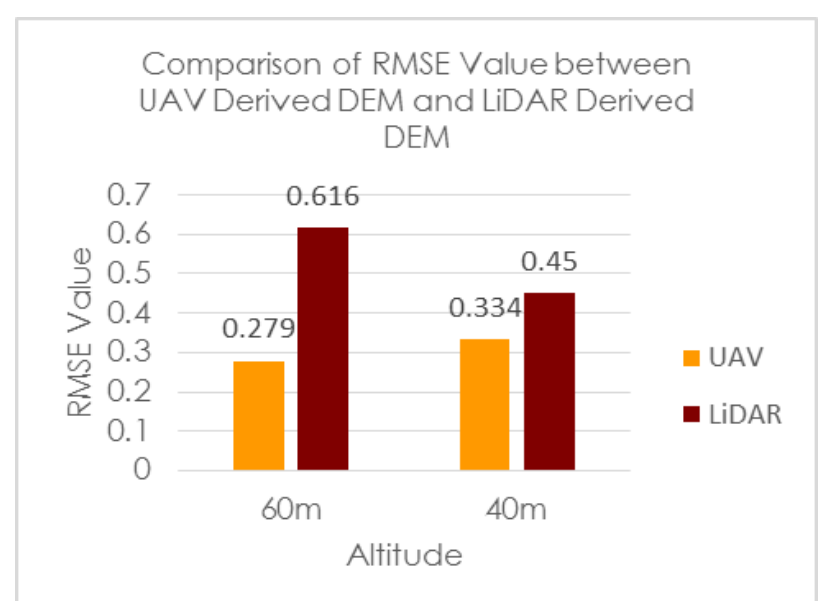

Figure 17. Comparison of RMSE Value between UAV Derived DEM and LiDAR Derived DEM 
The International Archives of the Photogrammetry, Remote Sensing and Spatial Information Sciences, Volume XLII-4/W16, 2019 6th International Conference on Geomatics and Geospatial Technology (GGT 2019), 1-3 October 2019, Kuala Lumpur, Malaysia

\begin{tabular}{|c|c|c|c|c|c|c|}
\hline \multirow{2}{*}{$\begin{array}{l}\text { Check } \\
\text { Point }\end{array}$} & \multicolumn{2}{|c|}{ DEM (UAV) } & \multicolumn{2}{|c|}{ DEM (LiDAR) } & \multicolumn{2}{|c|}{ DIFFERENCES } \\
\hline & $\mathrm{X}(\mathrm{m})$ & $\mathrm{Y}(\mathrm{m})$ & $\mathrm{X}(\mathrm{m})$ & $\mathrm{Y}(\mathrm{m})$ & $\mathrm{X}(\mathrm{m})$ & $\mathrm{Y}(\mathrm{m})$ \\
\hline CP 1 & 628845.994 & 173160.274 & 628845.613 & 173160.605 & 0.331 & -0.331 \\
\hline $\mathrm{CP} 2$ & 628881.001 & 173113.641 & 628881.001 & 173113.311 & 0 & 0.330 \\
\hline $\mathrm{CP} 3$ & 628917.712 & 173068.993 & 628917.712 & 173068.001 & 0 & 0.992 \\
\hline $\mathrm{CP} 4$ & 628970.298 & 173015.415 & 628970.629 & 173015.415 & -0.331 & 0 \\
\hline CP 5 & 628994.442 & 173076.600 & 628994.442 & 173077.592 & 0 & -0.992 \\
\hline \multirow[t]{3}{*}{ CP 6} & 629029.499 & 173128.193 & 629029.168 & 173128.193 & 0.331 & 0 \\
\hline & & & \multicolumn{2}{|c|}{ RMSE } & 0.234 & 0.604 \\
\hline & & & \multicolumn{2}{|c|}{ Average RMSE } & \multicolumn{2}{|c|}{0.279} \\
\hline
\end{tabular}

Table 6. Accuracy Assessment for UAV Derived DEM and LiDAR Derived DEM at 60m Altitude

\begin{tabular}{|c|c|c|c|c|c|c|}
\hline \multirow{2}{*}{$\begin{array}{c}\text { Check } \\
\text { Point }\end{array}$} & \multicolumn{2}{|c|}{ DEM (UAV) } & \multicolumn{2}{c|}{ DEM (LiDAR) } & \multicolumn{2}{c|}{ DIFFERENCES } \\
\cline { 2 - 7 } & $\mathrm{X}(\mathrm{m})$ & $\mathrm{Y}(\mathrm{m})$ & $\mathrm{X}(\mathrm{m})$ & $\mathrm{Y}(\mathrm{m})$ & $\mathrm{X}(\mathrm{m})$ & 0 \\
\hline CP 1 & 628845.994 & 173160.605 & 628845.944 & 173160.936 & 0 & -0.331 \\
\hline CP 2 & 628881.332 & 173113.311 & 628881.332 & 173113.311 & -0.992 & 0.331 \\
\hline CP 3 & 628916.720 & 173068.662 & 628917.712 & 173068.331 & 0.662 & 0.661 \\
\hline CP 6 & 629029.830 & 173128.193 & 629029.168 & 173127.532 & 0.596 & 0.405 \\
\hline & & & \multicolumn{2}{|c|}{ RMSE } & \multicolumn{2}{c|}{0.334} \\
\hline
\end{tabular}

Table 7. Accuracy Assessment for DEM between UAV and LiDAR at 40m Altitude

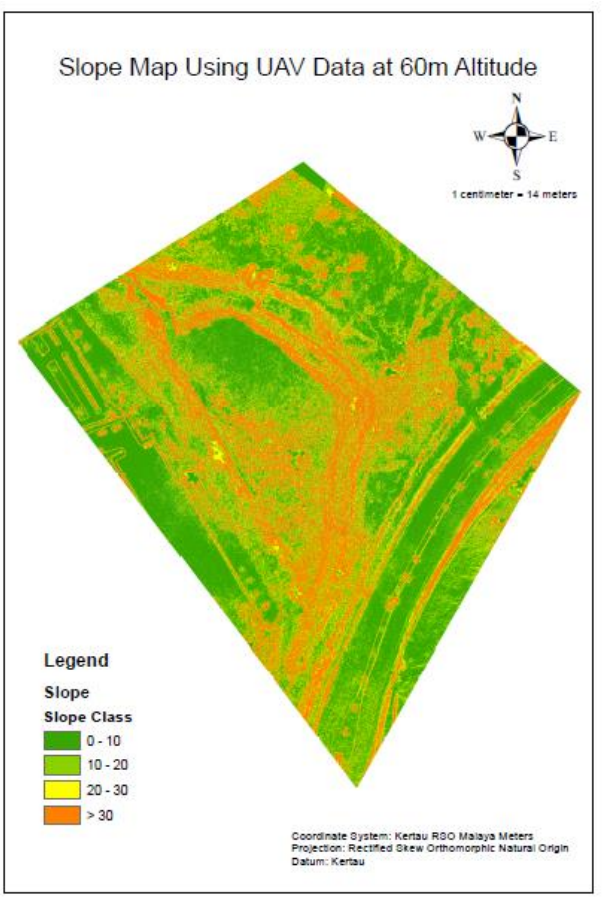

Figure 18. Slope Map Generated Using UAV Data at 60m Altitude

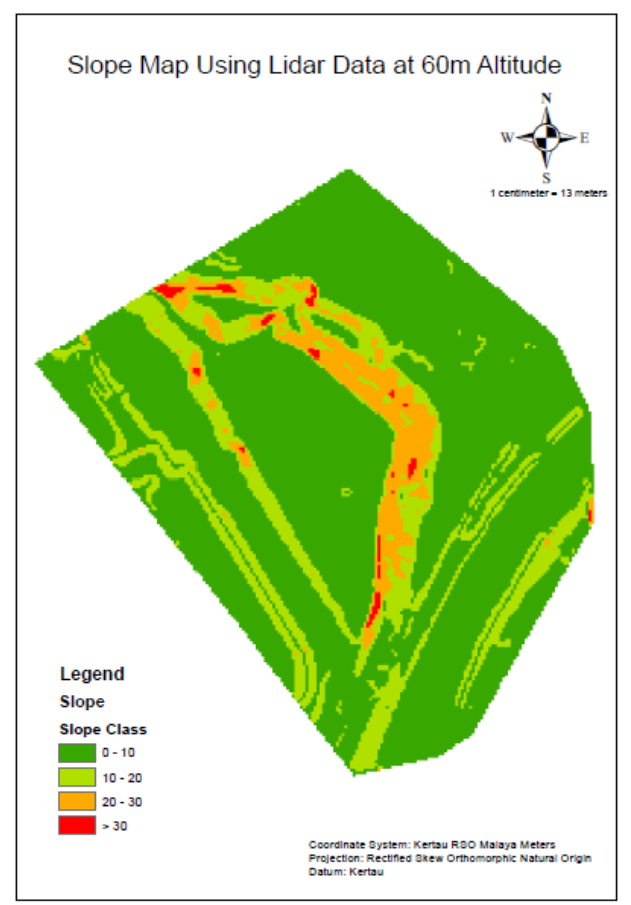

Figure 19. Slope Map Generated Using LiDAR Data at $60 \mathrm{~m}$ Altitude 
The International Archives of the Photogrammetry, Remote Sensing and Spatial Information Sciences, Volume XLII-4/W16, 2019 6th International Conference on Geomatics and Geospatial Technology (GGT 2019), 1-3 October 2019, Kuala Lumpur, Malaysia

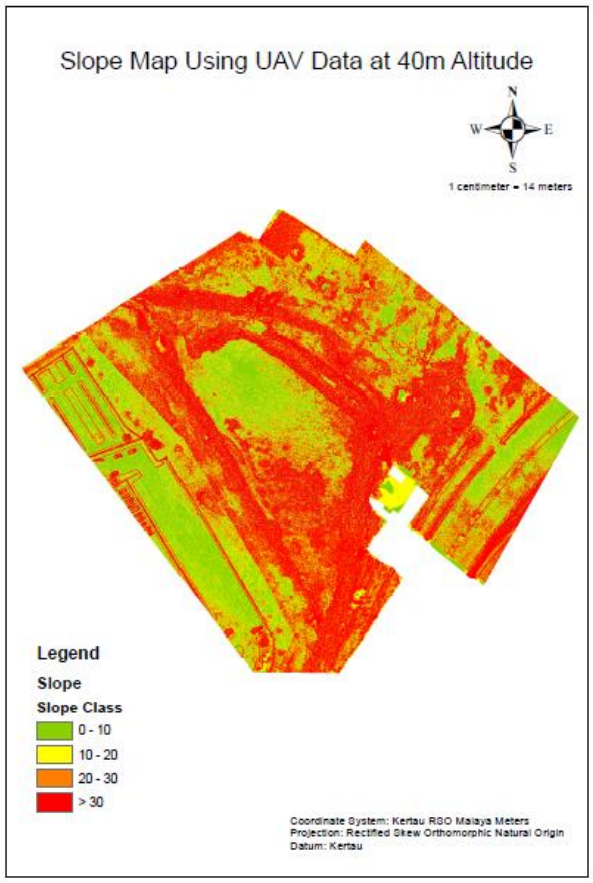

Figure 20. Slope Map Generated Using UAV Data at 40m Altitude

The slope map produced using UAV data was compared to the slope map produced using LiDAR data for both $60 \mathrm{~m}$ and $40 \mathrm{~m}$ altitude. Figure 18 and Figure 19 show the slope map generated using UAV and LiDAR data at $60 \mathrm{~m}$ altitude respectively while Figure 20 and Figure 21 depict the slope map generated using UAV and LiDAR data at 40m altitude respectively.

From the comparison, the slope map generated using LiDAR data is denser than the slope map generated using UAV data. This is due to the higher number LiDAR generated point cloud compared to the UAV generated point cloud. DEM was generated from dense point cloud (Uysal et al. 2015, Yunfei et al. 2008). However, less dense point cloud generated from UAV images can also produce a good slope map. The UAV generated slope can be seen clearly in the slope map.

In terms of slope classification, it can be seen that UAV generated slope can be classified better than LiDAR generated slope. Between two different altitudes, which is $60 \mathrm{~m}$ and $40 \mathrm{~m}$, the $60 \mathrm{~m}$ altitude UAV data produced better slope classification map than 40m altitude UAV data due to the failure of exterior orientation during aerial image processing which affect the elevation of the DEM.

\section{CONCLUSION}

In this study, UAV have been successfully used in order to investigate the capabilities of UAV in slope classification. Through this study, UAV can be used as a platform for slope classification with lower cost and maintenance since it also can produce good accuracy. This method can help to map and classify slope to prevent landslides by mapping the slope risk area so that the authorities can make a better decision when dealing with slope area. From the study, it is recommend that by using network real time kinematic global positioning system for processing the GCPs and CPs for improving the accuracy of orthophoto and DEM.

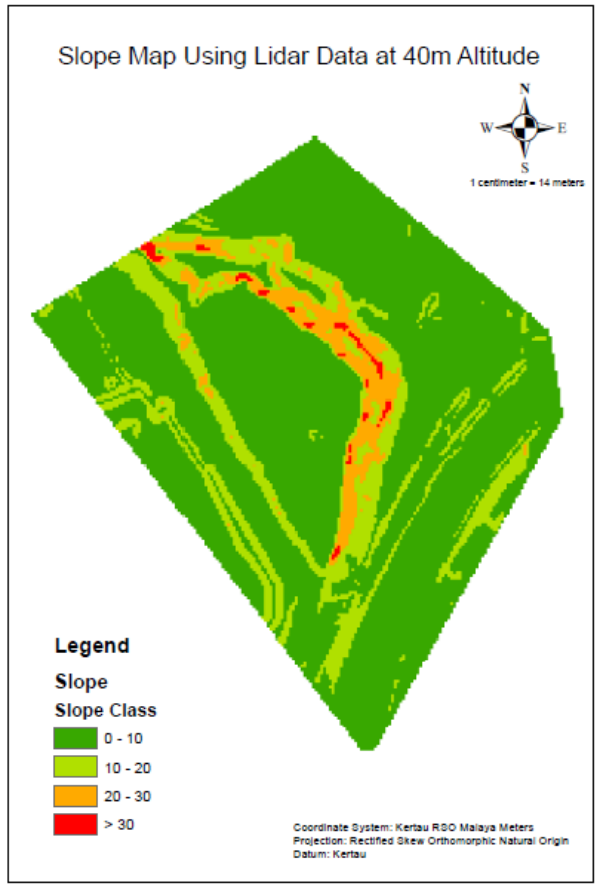

Figure 21. Slope Map Generated Using LiDAR Data at 40m Altitude

\section{ACKNOWLEDGEMENTS}

The authors would like to thank the Universiti Teknologi Malaysia (under research votes 5F054) for providing funding, instruments and experimental site.

\section{REFERENCES}

Azmi, S. M., Ahmad, B., \& Ahmad, A. (2014). Accuracy assessment of topographic mapping using UAV image integrated with satellite images. IOP Conference Series: Earth and Environmental Science, 18, 012015. doi:10.1088/1755$1315 / 18 / 1 / 012015$

Chao, H., Cao, Y., \& Chen, Y. (2007, August). Autopilots for small fixed-wing unmanned air vehicles: A survey. In Mechatronics and Automation, 2007. ICMA 2007. International Conference on (pp. 3144-3149). IEEE.

Fuad, N. (2016). The Capabilities of UAV-Based LiDAR for DTM Generation at Different Altitudes, Degree Thesis, Universiti Teknologi Malaysia.

Herwitz, S. R., Johnson, L. F., Dunagan, S. E., Higgins, R. G., Sullivan, D. V., Zheng, J., ... \& Slye, R. E. (2004). Demonstration of UAV-based imaging for agricultural surveillance and decision support. Computers and Electronics in Agriculture, 44, 49-61.

Peterman, V. (2015). Landslide Activity Monitoring With The Help Of Unmanned Aerial Vehicle. ISPRS - International Archives of the Photogrammetry, Remote Sensing and Spatial Information Sciences, XL-1/W4, 215-218. doi:10.5194/isprsarchives-xl-1-w4-215-2015 
Rau, J. Y., Jhan, J. P., Lo, C. F., \& Lin, Y. S. (2011). Landslide mapping using imagery acquired by a fixed-wing UAV. Int. Arch. Photogramm. Remote Sens. Spat. Inf. Sci, 38, 1-C22.

Remondino, F., Barazzetti, L., Nex, F., Scaioni, M., \& Sarazzi, D. (2011). UAV photogrammetry for mapping and $3 \mathrm{~d}$ modeling-current status and future perspectives. International Archives of the Photogrammetry, Remote Sensing and Spatial Information Sciences, 38(1), C22.

Rusli, M. A. (2017). The Comparison of Performance between Pix4D and Agisoft Photoscan Software to Produce Photogrammetric Product, Universiti Teknologi Malaysia.

Salleh, M. R. M., Ismail, Z., \& Rahman, M. Z. A. (2015). Accuracy assessment of lidar-derived digital terrain model (dtm) with different slope and canopy cover in tropical forest region. ISPRS Annals of the Photogrammetry, Remote Sensing and Spatial Information Sciences, 2(2), 183.

Step 1. Before Starting a Project 4. Getting GCPs on the field or through other sources (optional but recommended). (n.d.). Retrieved from https://support.pix4d.com/hc/enus/articles/202557489-Step-1-Before-Starting-a-Project-4Getting-GCPs-on-the-field-or-through-other-sources-optionalbut-recommended-

Tahar, K. N., Ahmad, A., \& Akib, W. W. M. (2011, December). UAV-based stereo vision for photogrammetric survey in aerial terrain mapping. In 2011 IEEE International Conference on Computer Applications and Industrial Electronics (ICCAIE) (pp. 443-447).

Tahar, K. N. (2012). A new approach on slope data acquisition using unmanned aerial vehicle. International Journal of Research and Reviews in Applied Sciences, 13(3), 780-785.

Tahar, K. N., Ahmad, A., Akib, W. A. A. W. M., \& Mohd, W. M. N. W. (2012). A new approach on production of slope map using autonomous Unmanned aerial vehicle. International journal of physical sciences, 7(42), 5678-5686.

Tahar, K. N. (2015). Multi rotor UAV at different altitudes for slope mapping studies. The International Archives of Photogrammetry, Remote Sensing and Spatial Information Sciences, 40(1), 9.

Tahar, K. N. (2015). Investigation on Different Scanning Resolutions for Slope Mapping Studies in Cameron Highlands, Malaysia. Arabian Journal for Science and Engineering, 40(1), 245-255

Uysal, M., Toprak, A. S., \& Polat, N. (2015). DEM generation with UAV Photogrammetry and accuracy analysis in Sahitler hill. Measurement, 73, 539-543.

Udin, W. S., Hassan, A. F., Ahmad, A., \& Tahar, K. N. (2012). Digital Terrain Model extraction using digital aerial imagery of Unmanned Aerial Vehicle. 2012 IEEE 8th International Colloquium on Signal Processing and Its Applications. doi:10.1109/cspa.2012.6194732

Yeh, F. H., Huang, C. J., Han, J. Y., \& Ge, L. (2018). Modeling Slope Topography Using Unmanned Aerial Vehicle Image Technique. In MATEC Web of Conferences (Vol. 147, p. 07002). EDP Sciences.

Yunfei, B., Guoping, L., Chunxiang, C., Xiaowen, L., Hao, Z., Qisheng, H., ... \& Chaoyi, C. (2008). Classification of LIDAR point cloud and generation of DTM from LIDAR height and intensity data in forested area. The International Archives of the Photogrammetry, Remote Sensing and Spatial Information Sciences, 37(7), 313-318

Revised August 2019 